\title{
Plasma glutamine status at intensive care unit admission: an independent risk factor for mortality in critical illness
}

\author{
Marie Smedberg ${ }^{*}(\mathbb{D}$, Johan Helleberg, Åke Norberg, Inga Tjäder, Olav Rooyackers and Jan Wernerman
}

\begin{abstract}
Background: A plasma glutamine concentration outside the normal range at Intensive Care Unit (ICU) admission has been reported to be associated with an increased mortality rate. Whereas hypoglutaminemia has been frequently reported, the number of patients with hyperglutaminemia has so far been quite few. Therefore, the association between hyperglutaminemia and mortality outcomes was studied in a prospective, observational study.

Patients and methods: Consecutive admissions to a mixed general ICU were eligible. Exclusion criteria were $<18$ years of age, readmissions, no informed consent, or a 'do not resuscitate' order at admission. A blood sample was saved within one hour from admission to be analysed by high-pressure liquid chromatography for glutamine concentration. Conventional risk scoring (Simplified Acute Physiology Score and Sequential Organ Failure Assessment) at admission, and mortality outcomes were recorded for all included patients.

Results: Out of 269 included patients, 26 were hyperglutaminemic ( $\geq 930 \mu \mathrm{mol} / \mathrm{L}$ ) at admission. The six-month mortality rate for this subgroup was $46 \%$, compared to $18 \%$ for patients with a plasma glutamine concentration $<930 \mu \mathrm{mol} / \mathrm{L}(P=0.002)$. A regression analysis showed that hyperglutaminemia was an independent mortality predictor that added prediction value to conventional admission risk scoring and age.

Conclusion: Hyperglutaminemia in critical illness at ICU admission was an independent mortality predictor, often but not always, associated with an acute liver condition. The mechanism behind a plasma glutamine concentration outside normal range, as well as the prognostic value of repeated measurements of plasma glutamine during ICU stay, remains to be investigated.
\end{abstract}

Keywords: Plasma glutamine, Critical illness, Hyperglutaminemia, Mortality, Liver failure

\section{Introduction}

A lower than normal plasma glutamine at ICU admission is associated with an increased mortality rate. Critically ill patients have an intracellular glutamine deprivation in skeletal muscle [1-3], which has been interpreted as a

\footnotetext{
*Correspondence: marie.smedberg@ki.se

Department of Anaesthesiology and Intensive Care, CLINTEC, Karolinska Institutet and Perioperative Medicine and Intensive Care, Karolinska University Hospital Huddinge Stockholm, B31 Perioperative Medicine and Intensive Care, Karolinska University Hospital Huddinge, 141 86 Stockholm, Sweden
}

whole body glutamine deficiency, associated with impairments in important metabolic functions. Enteral nutrition contains glutamine, but conventional intravenous nutrition does not. Therefore, supplementation with glutamine to critically ill patients has been suggested [4]. In particular, addition of a glutamine dipeptide to patients given parenteral nutrition. Several studies on glutamine supplementation of critically ill patients have been published, with variable and sometimes conflicting results [5-7]. Differences in inclusion criteria, doses and route of administration (enteral or parenteral) for the supplementation may partly explain the different results.

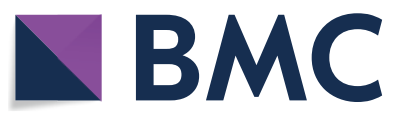

(c) The Author(s) 2021. Open Access This article is licensed under a Creative Commons Attribution 4.0 International License, which permits use, sharing, adaptation, distribution and reproduction in any medium or format, as long as you give appropriate credit to the original author(s) and the source, provide a link to the Creative Commons licence, and indicate if changes were made. The images or other third party material in this article are included in the article's Creative Commons licence, unless indicated otherwise in a credit line to the material. If material is not included in the article's Creative Commons licence and your intended use is not permitted by statutory regulation or exceeds the permitted use, you will need to obtain permission directly from the copyright holder. To view a copy of this licence, visit http://creativecommons.org/licenses/by/4.0/. The Creative Commons Public Domain Dedication waiver (http://creativeco mmons.org/publicdomain/zero/1.0/) applies to the data made available in this article, unless otherwise stated in a credit line to the data. 
One proposed mechanism for the negative effects of glutamine supplementation might be the inclusion of patients with high glutamine levels. Very few studies, though, contain information over the actual plasma concentration of glutamine at ICU admission, nor during the intervention. Thus, the original hypothesis that supplementation may be beneficial for subjects with a low plasma glutamine at ICU admission is still not tested [8], and the potential harmfulness of hyperglutaminemia is still obscure.

In parallel with glutamine supplementation for a potential deficit, some investigators suggest using glutamine as immunonutrition. This is derived from the multiple, critical metabolic processes with glutamine involvement, in particular for rapidly dividing cells, with important functions during sepsis and critical illness. Hence, the aim of some studies has not been just to normalize a low plasma glutamine, but rather to obtain pharmacological effects from glutamine supplementation. Moreover, this postulated pharmacological effect has been advocated for the sickest patients, despite the finding that hypoglutaminemia at ICU admission is not related to conventional risk scoring [9-11]. In the largest study investigating glutamine as an immunonutrient, glutamine was given at a very high dose, equalling $70 \%$ of the total nitrogen intake [12]. This resulted in a higher mortality in the supplemented group. Unfortunately, this contributed to the current guideline's advice, not only against using glutamine as immunonutrition, but also against glutamine supplementation for hypoglutaminemia at ICU admission [13].

The mechanism behind a plasma glutamine concentration out of the normal range is still obscure. The low glutamine associated with a high mortality may just be a biomarker without any mechanistic connection. Only a few publications include hyperglutaminemic ICU patients [9-11, 14-16]. A higher than normal plasma glutamine concentration is also reported to be associated with unfavourable outcomes, both at admission and during the course of critical illness $[9,11]$. As hyperglutaminemia is frequently observed among patients with liver insufficiency, several cohorts with impaired liver function were recently studied [17]. Acute on chronic liver failure and acute fulminant liver failure are often, but not always, accompanied by hyperglutaminemia, while chronic stable liver failure is not. The prognostic value of hyperglutaminemia in relation to liver failure is therefore not settled.

Although hypoglutaminemia is associated with an increased mortality, the predictive value of admission plasma glutamine concentration outside the normal range (low and high values together) turned out to be an even stronger mortality predictor statistically [9]. The subjects with high glutamine concentration were few in that report, but some of them suffered from liver failure.

In order to better define the possible predictive value of a higher than normal plasma glutamine concentration at ICU admission, we studied consecutive admissions to the ICU with special focus on liver function in a hypothesis generating observational study.

The study had several aims. The primary aim was to correlate the admission plasma glutamine concentration to routine clinical parameters. In particular to enable detection of likely hypoglutaminemia, associated with risk of unfavourable outcomes. This aim was not possible to address properly as the fraction of hypoglutaminemic patients was lower than expected and furthermore in the included cohort hypoglutaminemia was not associated with an unfavourable outcome. The possible reasons for this are put forward in the Discussion section below. Hence, a secondary aim, to further explore the relation between hyperglutaminemia at admission and outcomes as well as comorbidities, diagnoses, and clinical status, is presented here.

\section{Methods \\ Study protocol}

In this observational study, consecutive admissions to the general ICU of Karolinska University Hospital Huddinge between 2017-10-01-2018-07-01 were eligible for inclusion.

An extra tube of $4 \mathrm{ml}$ blood was sampled within one hour from admission to the ICU together with routine samples for risk scoring. Informed consent to analyse the sample had to be obtained within one month; otherwise, the sample was destructed. Data on risk scoring, cause of admission, basic characteristics of the patients, and mortality were collected from the patient records. The study is registered at ANZCTR, registration number 379071.

The individual result of plasma glutamine analysis was not known by the caregivers and had no impact on medical and nutritional treatment during hospital stay.

\section{Patients}

The general ICU of Karolinska University Hospital Huddinge is a mixed unit with both medical and surgical admissions. Surgical admissions are mainly upper abdominal and liver transplant, while cardiac, neuro, and traumas are handled at the other site of the Karolinska University Hospital. Exclusion criteria were (i) $<18$ years of age, (ii) a do not resuscitate order at admission, (iii) readmissions of patients already included into the study and, (iv) absence of informed consent.

Karolinska University Hospital Huddinge is one out of two centres for liver transplantation in Sweden. Most of the patients undergoing liver transplantation 
are transferred to the ICU post operatively, although the median ICU stay for this cohort is less than $24 \mathrm{~h}$. This group of patients was therefore identified and separated in the post hoc subgrouping (Additional file 1: Table 1B).

\section{Laboratory analysis}

The extra blood sample was collected in an ethylenediaminetetraacetic acid (EDTA) tube, centrifuged within one hour at $2000 \mathrm{xg}$, and plasma was then stored at -80 degrees Celsius pending analysis. Glutamine plasma concentrations were analysed as part of a complete aminogram using high-pressure liquid chromatography, as described previously (coefficient of variation 1.6\%) [9].

Routine laboratory tests were analysed at the hospital laboratory.

\section{Statistical analysis}

Results are presented as means \pm SD or median (interquartile range). Groups are compared with Student's t-test, Mann-Whitney U-test or Fisher's exact test as appropriate. Correlations are presented as Pearson's $\left(r^{2}\right)$ or Spearman rank correlation (rs). Kaplan-Meier curves and log rank test on survival were performed with IBM SPSS Statistics 24 (Statistical Package for Social Sciences, IBM, NY, USA, 2016). Software Statistica 13.2 (Dell Inc, Tulsa, OK USA) was used to perform univariate logistic regression and multiple logistic regression.

In our previous study, a receiver operating characteristic (ROC) curve for six-months mortality demonstrated a cut-off at plasma glutamine concentration $930 \mu \mathrm{mol} / \mathrm{L}$ or above [9]. Conventional risk scoring, Simplified Acute Physiology Score (SAPS 3) and Sequential Organ Failure Assessment (SOFA), has a high mortality prediction and was therefore included in the regression model. Age was also added as a separate risk factor, although it is already included in SAPS 3, because of its high impact on mortality and was demonstrated as significant also as an isolated predictor in the multiple regression analysis in our previous study [9].

To verify our cut-off for hyperglutaminemia, a ROC curve analysis of patients with a plasma glutamine concentration $>675 \mu \mathrm{mol} / \mathrm{L}$ compared with six-months mortality rate was performed using GraphPad Prism 8 (GraphPad Software Inc., San Diego, CA, USA). The inclusion criterion of values $>675 \mu \mathrm{mol} / \mathrm{L}$ to titrate the lower limit for possible risk was chosen based on the earlier publication [9].

Based on data from our previous study [9], the cut-off for hypoglutaminemia was $<400 \mu \mathrm{mol} / \mathrm{L}$.

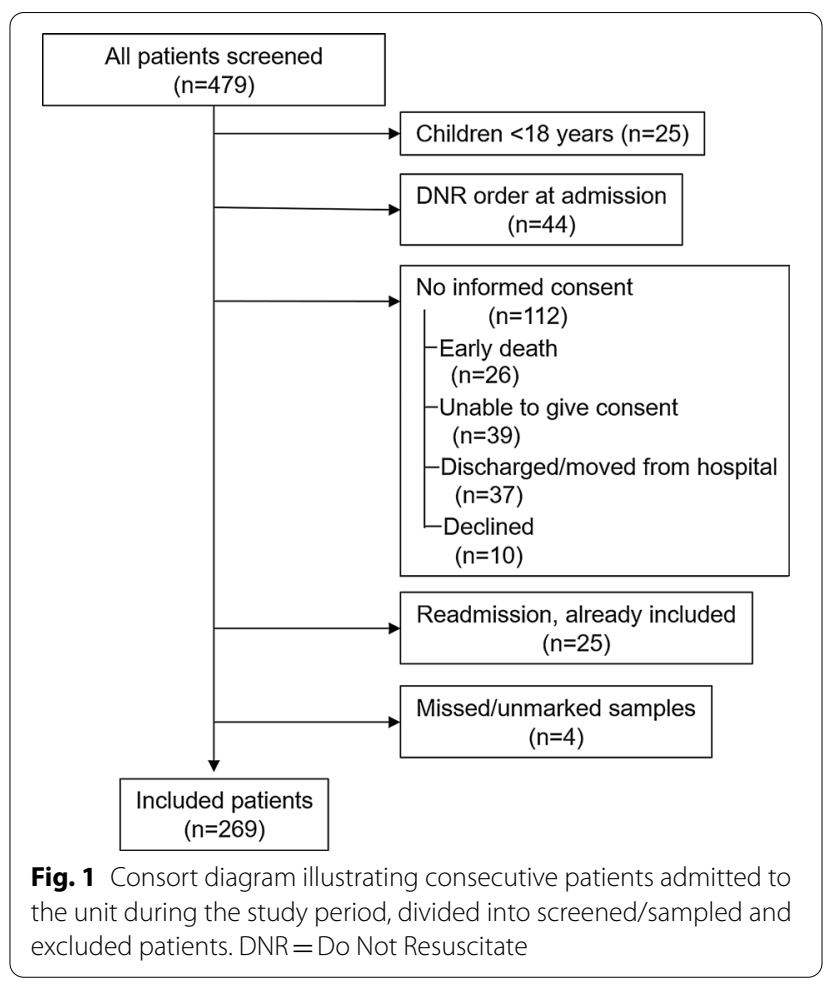

Table 1 Main diagnosis at ICU admission related to plasma glutamine concentration at admission

\begin{tabular}{|c|c|c|}
\hline $\begin{array}{l}\text { Main diagnosis at ICU } \\
\text { admission }\end{array}$ & $\begin{array}{l}\mathrm{p}- \\
\mathrm{Gln}<930 \mu \mathrm{mol} / \mathrm{L} \\
n(\%)\end{array}$ & $\begin{array}{l}\mathrm{p}- \\
\mathrm{G} \ln \geq 930 \mu \mathrm{mol} / \mathrm{L} \\
n(\%)\end{array}$ \\
\hline Postoperative liver transplant & $36(15)$ & $7(27)$ \\
\hline Liver failure & $5(2)$ & $7(27)$ \\
\hline Post cardiac arrest with ROSC & $16(7)$ & $2(8)$ \\
\hline Kidney failure & $11(5)$ & 0 \\
\hline Respiratory failure & $54(22)$ & $3(12)$ \\
\hline Sepsis/septic chock & $38(16)$ & $2(8)$ \\
\hline Intoxication & $17(7)$ & 0 \\
\hline Diabetic ketoacidosis & $5(2)$ & 0 \\
\hline Cardiac failure/shock & $9(4)$ & $1(4)$ \\
\hline Seizures & $9(4)$ & 0 \\
\hline Major bleeding & $11(5)$ & $2(8)$ \\
\hline Compromised airway & $9(4)$ & 0 \\
\hline Pancreatitis & $5(2)$ & $1(4)$ \\
\hline $\begin{array}{l}\text { Circulatory unstable (post- } \\
\text { surgery) }\end{array}$ & $5(2)$ & 0 \\
\hline Esophagus rupture/leak & $4(2)$ & 0 \\
\hline Other & $9(4)$ & $1(4)$ \\
\hline
\end{tabular}

ROSC, return of spontaneous circulation

\section{Results}

During the study period, 504 eligible patients were admitted to the general ICU, 479 patients were 
Table 2 Characteristics of subgroups according to plasma glutamine concentration at admission

\begin{tabular}{|c|c|c|c|c|c|c|}
\hline & All & $\mathrm{p}-\mathrm{Gln}<400 \mu \mathrm{mol} / \mathrm{L}$ & $\mathrm{p}-\mathrm{Gln} 400-930 \mu \mathrm{mol} / \mathrm{L}$ & $\mathrm{p}-\mathrm{Gln}<930 \mu \mathrm{mol} / \mathrm{L}$ & $\mathrm{p}-\mathrm{Gln} \geq 930 \mu \mathrm{mol} / \mathrm{L}$ & $p$ \\
\hline Number of patients & 269 & 40 & 203 & 243 & 26 & \\
\hline ICU mortality & $7 \%$ & $5 \%$ & $6 \%$ & $6 \%$ & $19 \%$ & 0.097 \\
\hline One-month mortality rate & $10 \%$ & $8 \%$ & $8 \%$ & $8 \%$ & $23 \%$ & 0.027 \\
\hline Six-months mortality rate & $21 \%$ & $20 \%$ & $18 \%$ & $18 \%$ & $46 \%$ & 0.002 \\
\hline SOFA & $6(3-8)$ & $5(3-8)$ & $6(3-8)$ & $5(3-8)$ & $7(5-11)$ & 0.006 \\
\hline SAPS 3 & $55 \pm 16$ & $59 \pm 14$ & $55 \pm 16$ & $55 \pm 16$ & $57 \pm 19$ & 0.593 \\
\hline Age (years) & $62(50-71)$ & $65(52-72)$ & $62(51-71)$ & $63(51-71)$ & $52(37-65)$ & 0.019 \\
\hline$p-G \ln (\mu \mathrm{mol} / L)$ & $585(469-735)$ & $353(317-371)$ & $594(518-700)$ & $557(456-676)$ & 1165 (998-1473) & $<0.001$ \\
\hline P-TAA (mmol/L) & $2.55(2.10-3.22)$ & $1.73(1.51-1.95)$ & $2.59(2.18-3.04)$ & $2.41(2.06-2.95)$ & $5.01(4.14-6.37)$ & $<0.001$ \\
\hline Liver disease $[n, \%]$ & $92(34 \%)$ & $9(23 \%)$ & $61(30 \%)$ & $70(29 \%)$ & $22(85 \%)$ & $<0.001$ \\
\hline Kidney failure $[n, \%]$ & $83(31 \%)$ & $14(35 \%)$ & $58(29 \%)$ & $72(30 \%)$ & $11(42 \%)$ & 0.187 \\
\hline
\end{tabular}

Means \pm SD or median and interquartile range

Significant $p$ values are indicated in bold

p-Gln, glutamine plasma concentration at admission; SOFA, Sequential Organ Failure Assessment; SAPS, Simplified Acute Physiology Score 3; P-TAA, total amino acid plasma concentration at admission; Liver disease, known liver disease, acute liver failure and/or acute liver damage; Kidney failure, kidney failure according to SAPS scoring and/or creatinine $>180 \mu \mathrm{mol} / \mathrm{L}$

$p$ value indicates the difference between the two groups $\mathrm{p}-\mathrm{Gln}<$ or $\geq 930 \mu \mathrm{mol} / \mathrm{L}$.

sampled, and 269 patients were finally included into the study (Fig. 1). The characteristics of the patients are given in Tables 1 and 2, including the subgroups according to plasma glutamine concentrations, and comorbidities, including liver disease. More extended characteristics are presented in the Additional file 1: Table 1A.

In the cohort of patients with hyperglutaminemia, the two major diagnoses for ICU admission were postoperative liver transplant and acute liver failure and $85 \%$ $(22 / 26)$ had liver disease and/or signs of acute liver damage at admission.

Admission hyperglutaminemia $(\geq 930 \mu \mathrm{mol} / \mathrm{L})$ was associated with a higher mortality rate $(n=26,19 \%$ in ICU, $23 \%$ at one month, and $46 \%$ at six months), as compared to admission plasma glutamine $<930 \mu \mathrm{mol} / \mathrm{L}$ $(n=243,6 \%$ in ICU, $8 \%$ at one month, and $18 \%$ at six months), $(P=0.002)$. This is illustrated in Fig. 2.

Out of the 26 patients with hyperglutaminemia, seven were admissions postoperatively after liver transplantation, and 19 were admitted for other reasons. The mortality rates for these sub-groups with hyperglutaminemia were $0 \%$ at six months for post liver transplantation and $21 \%$ in the ICU, $32 \%$ at one month, and $63 \%$ at six months $(P=0.01)$ for the other admission diagnoses. Out of the total cohort of patients included, $43 / 269$ were postoperative after liver transplantation, with a mortality rate of $0 \%$ at six months as compared to the mortality rates for the remaining patient group $(n=226)$ of $8 \%$ in the ICU, $12 \%$ at one month, and $21 \%$ at six months.
When a regression model was applied including all subjects $(n=269)$ to predict six months mortality rate, hyperglutaminemia was an independent predictor together with SAPS, admission SOFA and age (Table 3A, B). This finding was stronger when the postoperative liver transplantation subjects were excluded $(n=226)$ (Table 3C, D). Total plasma amino acid concentration was also included in the regression models, but that did not improve them.

A receiver operating characteristic (ROC) curve of patients with a plasma glutamine concentration $>675 \mu \mathrm{mol} / \mathrm{L}(n=88)$ compared with six-months mortality rate is presented in Fig. 3 . The area under the ROC curve (AUC) was $0.64(p=0.047)$, and the corresponding optimal cut-off value was $932 \mu \mathrm{mol} / \mathrm{L}$. If the postoperative liver transplanted patients are excluded, ROC AUC was $0.65(p=0.045)$ and the corresponding optimal cut-off value was $922 \mu \mathrm{mol} / \mathrm{L}(n=62)$.

\section{Discussion}

The main finding of the study is that hyperglutaminemia at ICU admission was associated with a more than two-fold higher mortality rate at six months compared to patients with normal or low plasma glutamine concentrations at admission. This finding was even stronger when subjects admitted to the ICU postoperatively after liver transplantation were excluded. Furthermore, hyperglutaminemia was a mortality predictor that added prediction value to conventional risk scoring and age.

The inclusion criteria applied in the present study were different from those used in an earlier report, when an association between hypoglutaminemia and a 


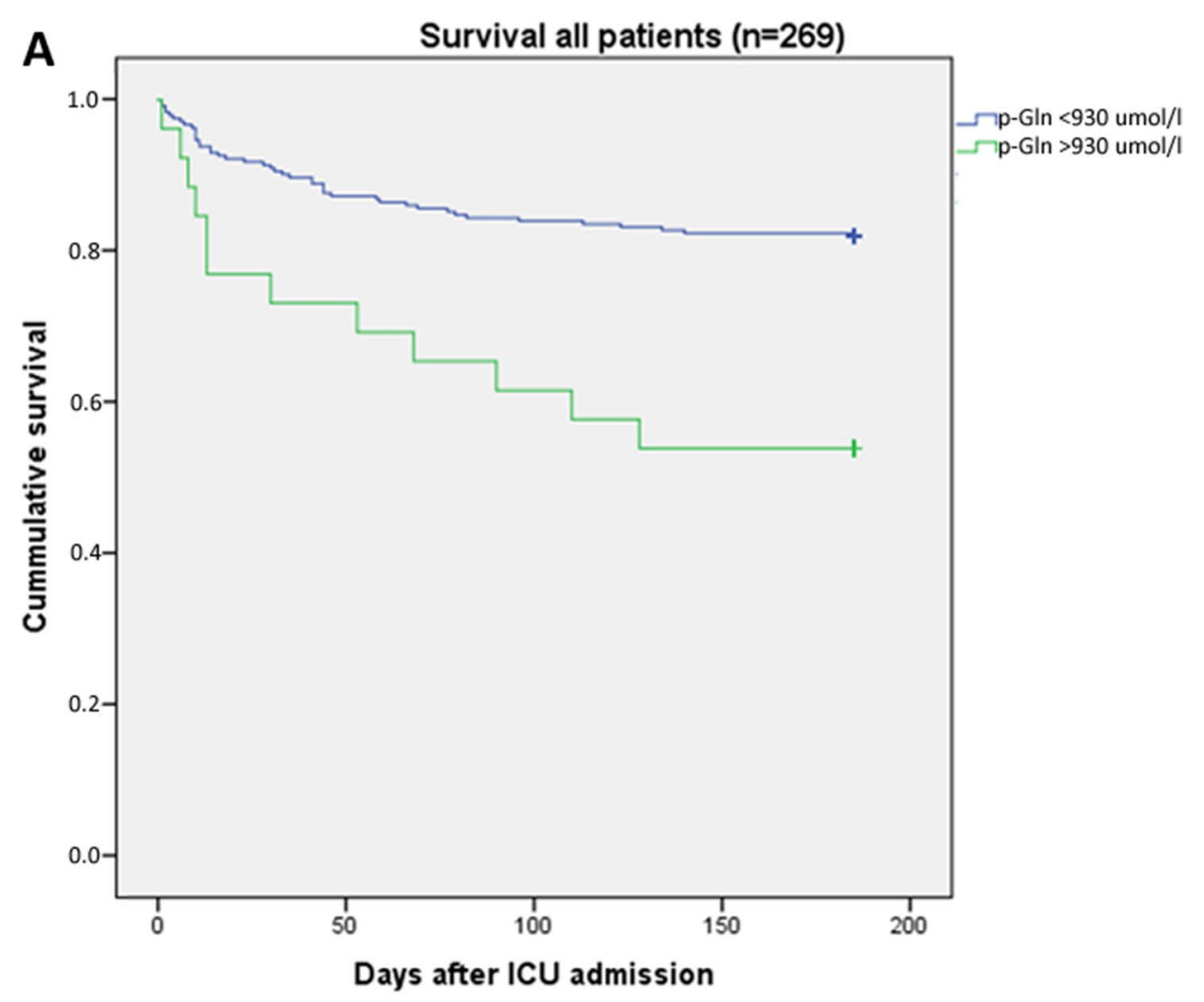

B Survival, postoperative liver tranplant excluded $(\mathrm{n}=226)$

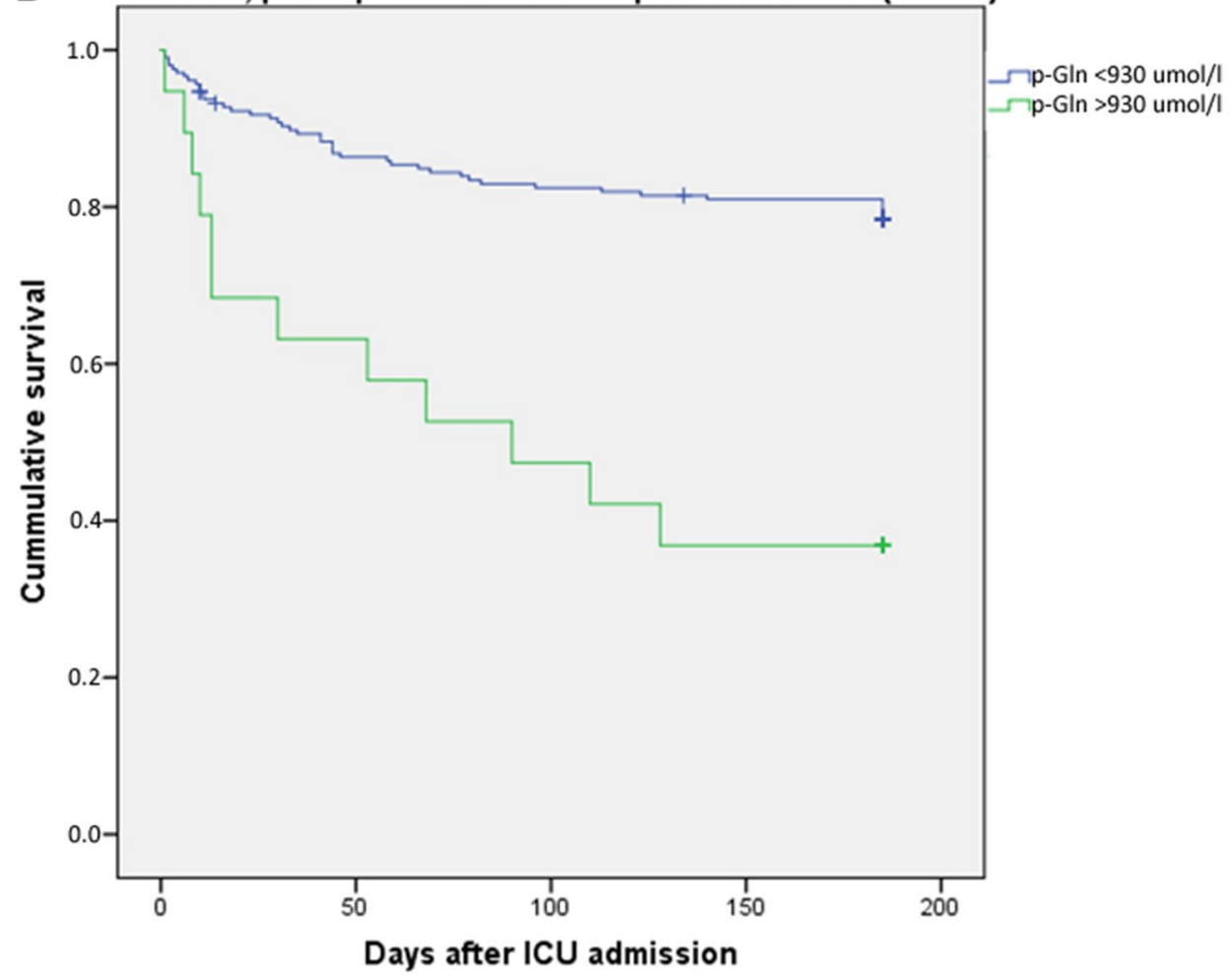

Fig. 2 Kaplan-Meier curves illustrating six months survival after ICU admission for patients with plasma glutamine concentration at admission $<930 \mu \mathrm{mol} / \mathrm{L}$ or $\geq 930 \mu \mathrm{mol} / \mathrm{L}$. Panel $\mathbf{A}$ shows all patients $(p=0.002)$ and in panel $\mathbf{B}$ with the postoperative liver transplant patients excluded $(p<0.001)$ 
Table 3 Logistic regression and multiple logistic regression in panels A and B for all patients, and in panels C and D with the postoperative liver transplant patients excluded

\begin{tabular}{|c|c|c|c|}
\hline Parameter & \multicolumn{2}{|c|}{ OR ( $95 \%$ confidence interval) } & $p$ value \\
\hline \multicolumn{4}{|c|}{ (A) Univariate logistic regression of six-months mortality rate in 269 ICU patients } \\
\hline $\mathrm{p}-\mathrm{G} \ln \geq 930 \mu \mathrm{mol} / \mathrm{L}$ & \multicolumn{2}{|c|}{$1.97(1.30-2.99)$} & 0.002 \\
\hline Age [per year] & \multicolumn{2}{|c|}{$1.038(1.014-1.063)$} & $<0.001$ \\
\hline SOFA score [per point] & \multicolumn{2}{|c|}{$1.18(1.09-1.27)$} & $<0.001$ \\
\hline SAPS score [per point] & \multicolumn{2}{|c|}{$1.042(1.022-1.063)$} & $<0.001$ \\
\hline All amino acids [per mmol/L] & \multicolumn{2}{|c|}{$1.12(0.96-1.31)$} & 0.059 \\
\hline Parameter & Beta & OR ( $95 \%$ confidence interval) & $p$ value \\
\hline \multicolumn{4}{|c|}{ (B) Multivariate logistic regression of six-months mortality rate in $269 \mathrm{ICU}$ patients } \\
\hline Intercept & -5.11 & & \\
\hline $\mathrm{p}-\mathrm{G} \ln \geq 930 \mu \mathrm{mol} / \mathrm{L}$ & 0.779 & $2.18(1.26-3.76)$ & 0.006 \\
\hline Age [per year] & 0.039 & $1.040(1.012-1.069)$ & 0.003 \\
\hline SOFA score [per point] & 0.114 & $1.12(1.02-1.23)$ & 0.015 \\
\hline SAPS score [per point] & 0.020 & $1.020(0.997-1.044)$ & 0.085 \\
\hline All Amino Acids [per mmol/L] & 0.006 & $1.006(0.876-1.155)$ & 0.932 \\
\hline Parameter & & confidence interval) & $p$ value \\
\hline \multicolumn{4}{|c|}{ (C) Univariate logistic regression of six-months mortality rate in 226 ICU patients } \\
\hline $\mathrm{p}-\mathrm{G} \ln \geq 930 \mu \mathrm{mol} / \mathrm{L}$ & & $4-4.13)$ & $<0.001$ \\
\hline Age [per year] & & $10-1.057)$ & 0.002 \\
\hline SOFA score [per point] & & $8-1.27)$ & $<0.001$ \\
\hline SAPS score [per point] & & $09-1.052)$ & 0.004 \\
\hline All amino acids [per mmol/L] & & $8-1.53)$ & 0.015 \\
\hline Parameter & beta & OR (95\% confidence interval) & $p$ value \\
\hline \multicolumn{4}{|c|}{ (D) Multivariate logistic regression for prediction of six-months mortality rate in 226 ICU patients } \\
\hline Intercept & -3.74 & & \\
\hline$p-G \ln \geq 930 \mu \mathrm{mol} / \mathrm{L}$ & 1.14 & $3.12(1.61-6.06)$ & $<0.001$ \\
\hline Age [per year] & 0.046 & $1.047(1.018-1.077)$ & $<0.001$ \\
\hline SOFA score [per point] & 0.160 & $1.17(1.06-1.30)$ & 0.001 \\
\hline SAPS score [per point] & -0.0056 & $0.994(0.968-1.021)$ & 0.679 \\
\hline All amino acids [per mmol/L] & -0.018 & $0.98(0.83-1.16)$ & 0.833 \\
\hline
\end{tabular}

p-Gln, glutamine plasma concentration at admission; SOFA, Sequential Organ Failure Assessment; SAPS, Simplified Acute Physiology Score 3

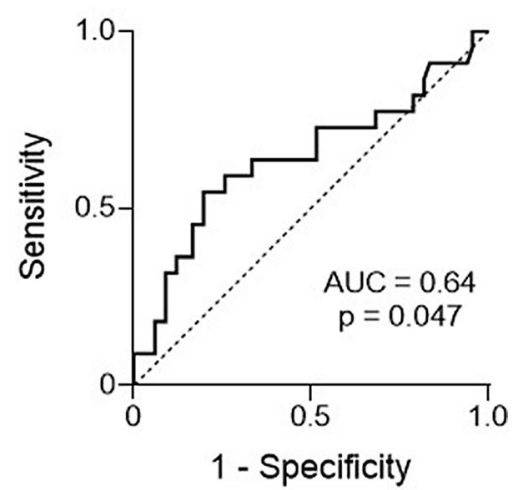

Fig. 3 ROC curve of patients with a plasma glutamine concentration $>675 \mu \mathrm{mol} / \mathrm{L}$ compared with six-months mortality $(n=88)$ higher mortality rate was demonstrated [9]. The exclusion of subjects with a 'Do Not Resuscitate' (DNR) order at admission and, in addition, the absence of informed consent after early deaths in the ICU leading to sample destruction, make the present cohort not comparable to that of the earlier publication, as illustrated in Table 2 . The present results, with only $15 \%$ of included admissions hypoglutaminemic $(<400 \mu \mathrm{mol} / \mathrm{L})$, should be contrasted to around one third in earlier reports. Furthermore, the overall six-months mortality rate of the included patients was $21 \%(58 / 269)$, while the estimated mortality rate among the excluded patients would be $>40 \%$, if all patients with DNR orders were assumed dead during the six months follow-up period. So, the selected patient cohort included in the present study was clearly different 
from other publications [9]. Hence, our present data cannot confirm, but also not contradict, the observations that hypoglutaminemia at ICU admission is associated with an increased mortality rate. This imperfection is unfortunate, but simultaneously it points out the difficulty to compare published patient cohorts, when the inclusion criteria are not meticulously communicated.

The regression analysis showed hyperglutaminemia as a strong mortality predictor also in addition to risk scoring and age. In a selected cohort, as ours, it is common that admission SOFA gives a higher prediction than SAPS 3 due to a stronger reflection of the actual organ failures.

Also, the previous finding of a cut-off for predicting mortality of $930 \mu \mathrm{mol} / \mathrm{L}$ was confirmed, and high plasma glutamine concentration is strengthened as an independent predictor of six-months mortality rate in the ICU setting.

The co-existence of hyperglutaminemia and liver conditions has been shown before [18-22]. It has been connected to the hyperammonemia frequently found in liver conditions, but without any settled mechanism for this observation. Enteral glutamine loading has even been suggested as a diagnostic tool for hepatic encephalopathy [23], however, with limited external acceptance. Up-todate differentiation of separate cohorts within the group of patients with liver conditions has enabled a more selective view upon the connection between hyperglutaminemia and compromised liver function [17]. In our recent report over plasma glutamine levels in four different cohorts of liver conditions, a general connection between severity of liver disease and plasma glutamine levels was found (AUC for ROC curves 0.75 and 0.82 for Child-Pugh score and Model of End-stage Liver Disease score, respectively) [17]. Hyperglutaminemia was mainly confined to the cohorts with acute fulminant and acute on chronic liver diseases, while chronic liver disease and liver mass reduction by surgery only marginally deviated from normal.

The liver has a crucial role in glutamine metabolism and balance [24]. An impaired liver function can therefore significantly contribute to deranged, high plasma glutamine levels. Accordingly, higher plasma concentrations of bilirubin, alanine aminotransferase, aspartate transaminase, and lactate were associated with high plasma glutamine in our cohort (Additional file 1: table $1 \mathrm{~A}$ and $1 \mathrm{~B}$ ). Furthermore, it has been suggested that cell damage may result in high plasma glutamine, due to leakage of intracellular glutamine from the destroyed cells into plasma [10], as intracellular glutamine concentrations greatly exceed plasma concentration in many tissues [25-28]. An elevated plasma creatine phosphokinase level as an indicator of cell damage is reported in sepsis patients with high plasma glutamine [10], which supports this hypothesis. Unfortunately, creatine phosphokinase is not a routine sample in our ICU and, therefore, this could not be explored in the present cohort.

It is an interesting observation that the hyperglutaminemic patients undergoing liver transplantation exhibited no mortality during the observation period. Although few in numbers, this observation suggests that a functional liver may be important for normalising the plasma amino acid pattern. Furthermore, in the present cohort of critically ill patients, we find no example where an isolated high glutamine, without connection to a severe pathology, is associated with mortality. The pathophysiology behind the high plasma glutamine levels is likely multifactorial. Glutamine kinetics needs to be further studied in the hyperglutaminemia subgroup to better understand the mechanisms.

There are several limitations in our present study. Most important, the failure to reproduce the connection between hypoglutaminemia and mortality due to the broad exclusion criteria applied, commented upon above. The question is if this may invalidate our main result? We don't think so, because if the assumption over mortality for the excluded patients is combined with the assumption that none of these individuals were hyperglutaminemic, the hypothetical mortality still comes out statistically different ( $46 \%$ vs. $29 \%$, also with the post liver transplant patients included). Thus, we think that the relatively large number of hyperglutaminemia subjects, make that this report adds value to our understanding of admission glutaminemia, as a biomarker or a reflection of overall glutamine status. The strength of the study is the pragmatic design with virtually no missing data.

In summary, admission hyperglutaminemia $(\geq 930 \mu \mathrm{mol} / \mathrm{L})$ is a prognostic sign for high mortality, which adds predictive value to conventional admission scoring (SAPS 3, SOFA). Hyperglutaminemia is often connected to liver conditions, but is also observed in patients without signs of liver affection. The study is observational in character and measurements of glutamine rates of appearance and disappearance in hyperglutaminemic subjects, as well as repeated sampling during ICU stay, will be needed for better understanding. When plasma glutamine concentration is available in clinical practice and hyperglutaminemia is present, repeated sampling is recommended, and actions should be considered if the level is not decreasing, such as limited protein/amino acid intake.

\section{Conclusion}

Hyperglutaminemia present at ICU admission was an independent mortality predictor for critically ill patients. The presence of hyperglutaminemia was often, but 
not always, associated with an acute liver condition. In postoperative liver transplanted patients, plasma glutamine concentration was not related to mortality. The mechanism behind an elevated plasma glutamine concentration, as well as the prognostic value of repeated measurements of plasma glutamine during ICU stay, remains to be investigated.

\begin{abstract}
Abbreviations
AUC: Area under the curve; DNR: Do not resuscitate; Gln: Glutamine; ICU: Intensive care unit; ROC: Receiver operating characteristic; ROSC: Return of spontaneous circulation; SAPS: Simplified Acute Physiology Score; SOFA: Sequential Organ Failure Assessment.
\end{abstract}

\section{Supplementary Information}

The online version contains supplementary material available at https://doi. org/10.1186/s13054-021-03640-3.

Additional file 1. Patient characteristics: Characteristics of high glutamine patients versus normal glutamine patients in all patients (Table 1A) and with newly liver transplanted patients are excluded (Table 1B).

\section{Acknowledgements}

We want to acknowledge the excellent nursing assistance from Kristina Kilsand, Sara Rydén and Janelle Cederlund and the skilled technical assistance from Eva Nejman.

\section{Authors' contributions}

Conception and design of the study were contributed by MS, OR, JW. Acquisition of data was contributed by MS, JH, IT. Analysing, calculations and interpretation of data were contributed by MS, JH, IT, ÅN, OR, JW. Reagents/ materials/analysis tools were contributed by MS, ÅN, OR. Writing the paper was contributed by MS, JH, IT, ÅN, OR, JW. All authors read and approved the final manuscript.

\section{Funding}

Open access funding provided by Karolinska Institute. This study was supported by grants from the County Council of Stockholm and the Swedish Medical Research Council.

\section{Availability of data and materials}

Extended data on patient characteristics available in pdf Additional file 1.

\section{Declarations}

\section{Ethical approval and consent to participate}

Informed consent after information of the study protocol orally and in writing was obtained from the patient or, when not possible, from a close relative. The protocol complied with the ethical guidelines of the Declaration of Helsinki and was approved by the Regional Ethical Review Board, Stockholm, Sweden.

\section{Consent for publication}

Not applicable.

\section{Competing interests}

The authors declare that they have no competing interests.

Received: 26 February 2021 Accepted: 11 June 2021

Published online: 07 July 2021

\section{References}

1. Tjäder I, Rooyackers O, Forsberg AM, Vesali RF, Garlick PJ, Wernerman J. Effects on skeletal muscle of intravenous glutamine supplementation to ICU patients. Intensive Care Med. 2004;30(2):266-75.

2. Gamrin L, Andersson K, Hultman E, Nilsson E, Essén P, Wernerman J. Longitudinal changes of biochemical parameters in muscle during critical illness. Metabolism. 1997;46(7):756-62.

3. Biolo G, Zorat F, Antonione R, Ciocchi B. Muscle glutamine depletion in the intensive care unit. Int J Biochem Cell Biol. 2005:37(10):2169-79.

4. Berger MM. The 2013 Arvid Wretlind lecture: evolving concepts in parenteral nutrition. Clin Nutr. 2014;33(4):563-70.

5. Stehle P, Ellger B, Kojic D, Feuersenger A, Schneid C, Stover J, et al. Glutamine dipeptide-supplemented parenteral nutrition improves the clinical outcomes of critically ill patients: a systematic evaluation of randomised controlled trials. Clin Nutr ESPEN. 2017;17:75-85.

6. Mottaghi A, Yeganeh MZ, Golzarand M, Jambarsang S, Mirmiran P. Efficacy of glutamine-enriched enteral feeding formulae in critically ill patients: a systematic review and meta-analysis of randomized controlled trials. Asia Pac J Clin Nutr. 2016;25(3):504-12.

7. Oldani M, Sandini M, Nespoli L, Coppola S, Bernasconi DP, Gianotti L. Glutamine supplementation in intensive care patients: a meta-analysis of randomized clinical trials. Medicine (Baltimore). 2015;94(31):e1319.

8. Smedberg M, Wernerman J. Is the glutamine story over? Crit Care. 2016:20(1):361.

9. Rodas PC, Rooyackers O, Hebert C, Norberg A, Wernerman J. Glutamine and glutathione at ICU admission in relation to outcome. Clin Sci. 2012;122(11-12):591-7.

10. Oudemans-van Straaten HM, Bosman RJ, Treskes M, van der Spoel HJ, Zandstra DF. Plasma glutamine depletion and patient outcome in acute ICU admissions. Intensive Care Med. 2001;27(1):84-90.

11. Tsujimoto T, Shimizu K, Hata N, Takagi T, Uejima E, Ogura H, et al. Both high and low plasma glutamine levels predict mortality in critically ill patients. Surg Today. 2017:47(11):1331-8.

12. Heyland D, Muscedere J, Wischmeyer PE, Cook D, Jones G, Albert M, et al. A randomized trial of glutamine and antioxidants in critically ill patients. $\mathrm{N}$ Engl J Med. 2013;368(16):1489-97.

13. Singer $P$, Blaser AR, Berger MM, Alhazzani W, Calder PC, Casaer MP, et al. ESPEN guideline on clinical nutrition in the intensive care unit. Clin Nutr. 2019;38(1):48-79.

14. Nienaber A, Dolman RC, van Graan AE, Blaauw R. Prevalence of glutamine deficiency in ICU patients: a cross-sectional analytical study. Nutr J. 2016;15(1):73.

15. Heyland DK, Elke G, Cook D, Berger MM, Wischmeyer PE, Albert M, et al. Glutamine and antioxidants in the critically ill patient: a post hoc analysis of a large-scale randomized trial. JPEN J Parenter Enteral Nutr. 2015;39(4):401-9.

16. Blaauw R, Nel DG, Schleicher GK. Plasma glutamine levels in relation to intensive care unit patient outcome. Nutrients. 2020;12(2):402.

17. Helling G, Wahlin S, Smedberg M, Pettersson L, Tjäder I, Norberg $\AA$, et al. Plasma glutamine concentrations in liver failure. PLoS ONE. 2016;11(3):e0150440.

18. Clemmesen JO, Kondrup J, Ott P. Splanchnic and leg exchange of amino acids and ammonia in acute liver failure. Gastroenterology. 2000:118(6):1131-9.

19. Rama Rao KV, Jayakumar AR, Norenberg MD. Glutamine in the pathogenesis of acute hepatic encephalopathy. Neurochem Int. 2012:61(4):575-80.

20. Lemberg A, Fernández MA. Hepatic encephalopathy, ammonia, glutamate, glutamine and oxidative stress. Ann Hepatol. 2009;8(2):95-102.

21. Olde Damink SW, Jalan R, Redhead DN, Hayes PC, Deutz NE, Soeters PB. Interorgan ammonia and amino acid metabolism in metabolically stable patients with cirrhosis and a TIPSS. Hepatology. 2002;36(5):1163-71.

22. Ott P, Vilstrup H. Cerebral effects of ammonia in liver disease: current hypotheses. Metab Brain Dis. 2014;29(4):901-11.

23. Romero-Gómez M, Grande L, Camacho I. Prognostic value of altered oral glutamine challenge in patients with minimal hepatic encephalopathy. Hepatology. 2004;39(4):939-43

24. Bode BP, Souba WW. Glutamine transport and human hepatocellular transformation. JPEN J Parenter Enteral Nutr. 1999;23(5 Suppl):S33-7.

25. Ahlman B, Ljungqvist $O$, Persson B, Bindslev L, Wernerman J. Intestinal amino acid content in critically ill patients. JPEN J Parenter Enteral Nutr. 1995; 19(4):272-8 
26. Januszkiewicz A, Essén P, McNurlan MA, Calder GA, Andersson K, Wernerman J, et al. Effect of a short-term infusion of glutamine on muscle protein metabolism postoperatively. Clin Nutr. 1996;15(5):267-73.

27. Barle H, Ahlman B, Nyberg B, Andersson K, Essén P, Wernerman J. The concentrations of free amino acids in human liver tissue obtained during laparoscopic surgery. Clin Physiol. 1996;16(3):217-27.

28. Roth E, Funovics J, Mühlbacher F, Schemper M, Mauritz W, Sporn P, et al. Metabolic disorders in severe abdominal sepsis: glutamine deficiency in skeletal muscle. Clin Nutr. 1982;1(1):25-41.

\section{Publisher's Note}

Springer Nature remains neutral with regard to jurisdictional claims in published maps and institutional affiliations.
Ready to submit your research? Choose BMC and benefit from:

- fast, convenient online submission

- thorough peer review by experienced researchers in your field

- rapid publication on acceptance

- support for research data, including large and complex data types

- gold Open Access which fosters wider collaboration and increased citations

- maximum visibility for your research: over $100 \mathrm{M}$ website views per year

At BMC, research is always in progress.

Learn more biomedcentral.com/submissions 